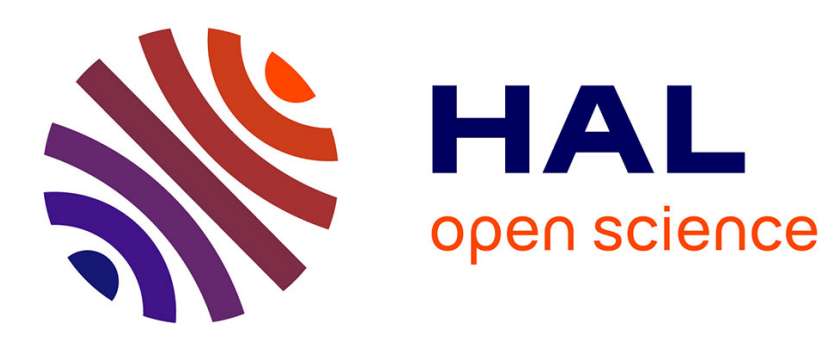

\title{
Les Théoriciens Italiens de la Raison D'État Carrières et Motivations
}

\author{
Cremer Albert
}

\section{To cite this version:}

Cremer Albert. Les Théoriciens Italiens de la Raison D'État Carrières et Motivations. Revue de Synthèse, 2009, 130 (3), pp.425-445. 10.1007/s11873-009-0085-4 . hal-00523667

\section{HAL Id: hal-00523667 \\ https://hal.science/hal-00523667}

Submitted on 6 Oct 2010

HAL is a multi-disciplinary open access archive for the deposit and dissemination of scientific research documents, whether they are published or not. The documents may come from teaching and research institutions in France or abroad, or from public or private research centers.
L'archive ouverte pluridisciplinaire $\mathbf{H A L}$, est destinée au dépôt et à la diffusion de documents scientifiques de niveau recherche, publiés ou non, émanant des établissements d'enseignement et de recherche français ou étrangers, des laboratoires publics ou privés. 


\title{
LES THÉORICIENS ITALIENS DE LA RAISON D'ÉTAT CARRIÈRES ET MOTIVATIONS
}

\begin{abstract}
Albert CREMER*
RÉSUMÉ: L'article cherche à mettre en lumière les carrières et les motivations des auteurs italiens qui ont écrit sur la raison d'État entre 1550 et 1650. La moitié d'entre eux furent des ecclésiastiques aux positions très différentes auxquels se joignaient juristes, médecins et gens de lettres. Nombre d'ecclésiastiques enseignaient dans les universités et tentaient d'obtenir un poste de secrétaire ou de conseiller à la cour, auprès d'un prince ou d'un cardinal. D'autres motifs les poussaient à rédiger leurs traités: la réprobation des idées de Machiavel, l'ouverture d'espaces d'action pour le prince, mais aussi la défense des libertés républicaines. Ces traités et recueils de maximes proposent surtout un savoir littéraire. Leur influence sur la rationalisation de l'État est ici analysée de manière sceptique.
\end{abstract}

MotS-CLÉs : raison d'État, auteurs italiens, carrières, motivations.

\section{ITALIAN THEORISTS OF THE REASON OF STATE CAREERS AND MOTIVATIONS}

ABSTRACT: The article tries to shed light on the careers and the motivations of Italian authors who wrote on reason of State in the period of 1550 to 1650. Half of them were clergymen in very different positions, joined by lawyers, physicians and men of letters. Especially many clergymen were teaching at universities in the hope of getting a position at a court. Apart from this endeavour to become a secretary or councillor of a prince or a cardinal, the main motivations of writing the treatises were the refutation of the machiavellian ideas and the desire to open new areas of action for the prince, but also the defence of republican liberties. As the treatises and collections of maxims were to a great extent literary, the influence on rationalisation of the State is judged with scepticism.

KEYWORDS: reason of State, Italian authors, careers, motivations.

\footnotetext{
* Albert Cremer, né en 1941, historien, ancien chercheur à l'Institut Max-Planck de Göttingen, travaille sur la magistrature parisienne des $\mathrm{XVI}^{\mathrm{e}}$ et $\mathrm{XVII}^{\mathrm{e}}$ siècles et sur la philosophie politique de la même époque. Il a notamment publié Der Adel in der Verfassung des Ancien Régime: die Châtellenie d'Epernay und die Souveraineté de Charleville im 17. Jahrhundert (Bonn, Röhrscheid, 1981) et différents articles dont « La genèse du droit des gens moderne et la conscience européenne: Francisco De Vitoria et Jean Bodin », dans La Conscience européenne au XVI et au XVII siècle (Paris, ENSJF, 1982).

Adresse: Breslauer Str. 24, D-37085 Göttingen.

Courrier électronique: CremerAlbert@gmx.de
} 


\section{DIE ITALIENISCHEN THEORETIKER DER STAATSRÄSON KARRIEREN UND MOTIVATIONEN}

Zusammenfassung: Der Artikel ist bestrebt, die Karrieren und Motivationen italienischer Autoren der Zeit von 1550-1650 zu erhellen, die über die Staatsräson geschrieben haben. Von ihnen waren die Hälfte Geistliche in sehr unterschiedlichen Positionen, hinzu kamen Juristen, Mediziner und gens de lettres. Viele Kleriker lehrten an Universitäten und versuchten, eine Position als Sekretär oder Rat bei einem geistlichen oder weltlichen Fürsten zu erlangen. Auch andere Motive waren für die Niederschrift der Traktate wichtig, insbesondere die Abwehr der Ideen Machiavellis, die Eröffnung neuer Handlungsspielräume für den Fürsten, aber auch die Verteidigung republikanischer Freiheiten. Da die Traktate und Maximensammlungen im wesentlichen literarisches Wissen vermittelten, wird der Einfluss auf die Rationalisierung des Staates skeptisch beurteilt.

STICHWÖRTER: Staatsräson, italienische Autoren, Karrieren, Motivationen.

$$
\text { ألبار كريمار : منظّرون إيطاليون لمصلحة الدولة. مسار ات ودو افع. }
$$

ملخَّص: نريد من خلال هذا المقال إلقاء الضَّو ء على مسار ات و أهداف الكتَّاب الإيطاليّيّن الذين ألَّفوا

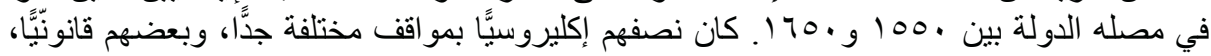

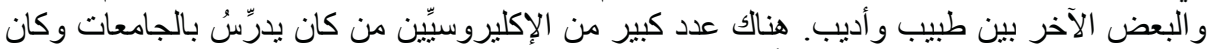

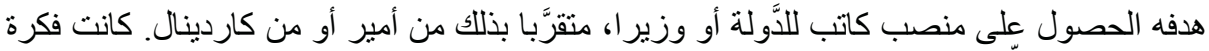

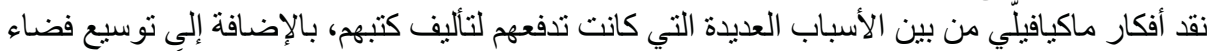

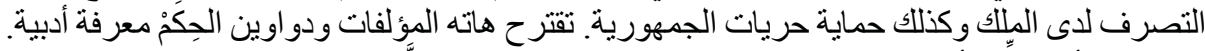

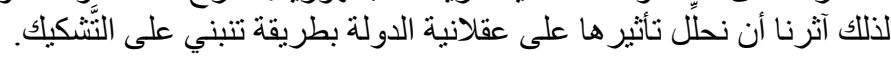

$$
\text { الكلمات المفاتيح: مصلحة الدولة، مؤلفون إيطاليون، مسار ات، دو افع. }
$$

国益に関するイタリアの理論家

活動の舞台と動機

$$
\text { アルベート・クレメール }
$$

要約 : ここでは、1550年から1650年にかけて、国益に関するイタリア人著者 の活動の場と動機について取り上げたい。著者の大半は聖職者であり、法律 家、医者、文学者が仲間入りする陣営とはかけ離れていた。聖職者たちの多 くは、大学で教鞭をとりながら宮廷の王や枢機卿の秘書、参事の役職などを 探していた。またそれ以外に各々の論文を作成していた。例えば、マキアベ リスト思想の弾劾、君主の活動範囲の拡大、共和国の自由の擁護など。これ らの論文や格言集では、特に文学的知識の重要性を説いていた。ここでは、 この文学的知識が国家の合理化に及ぼす影響について懐疑的に分析したい。

キーワード : 国益、イタリア人著者、活動の舞台、動機 
$\mathrm{L}$ es mutations de l'univers politique en Europe au $\mathrm{XVI}^{\mathrm{e}}$ siècle ont suscité l'apparition d'une vaste littérature politique: l'évolution progressive des structures féodales vers de puissants États centralisés, administratifs et désacralisés, mais dont l'Italie semblait être exclue, donna lieu à une multiplicité d'ouvrages. Cette littérature scrutait les événements sur des bases livresques (le modèle de l'Antiquité), en fonction d'expériences (de courtisans, d'ambassadeurs) et de spéculations particulières. Elle se proposait des buts très divers: mettre fin à ce qui était alors ressenti comme un déclin généralisé afin de ressusciter une nouvelle civilisation; condamner les thèses de Machiavel ou, au contraire, les rendre plus ou moins compatibles avec la morale chrétienne; défendre les libertés républicaines; faire l'éloge de l'État absolutiste. Il s'agissait, en somme, de rationaliser le fonctionnement de l'État pour le rendre efficace comme jadis l'Empire romain et, pour quelques-uns, l'Empire ottoman. Ces ouvrages qui traitaient de la raison d'État et du tacitisme prospéraient, notamment en Italie et en France, au cours du XVI ${ }^{\mathrm{e}}$ siècle et dans la première moitié du XVII ${ }^{\mathrm{e}}$ siècle. Pour la seule période qui va de 1550 à 1650, Tommaso Bozza a repéré plus de 180 titres pour l'Italie et sa recension était loin d'être exhaustive' ${ }^{1}$. La production politico-littéraire répondait alors, sans doute, à un vif intérêt du public: même si l'écrasante majorité des ouvrages tombait dans l'oubli, d'autres connaissaient un succès remarquable.

La notion de raison d'État est apparue dans les années 1520 chez François Guichardin ${ }^{2}$ et Giovanni Della Casa ${ }^{3}$. La réprobation officielle de l'œuvre de Machiavel et le réalisme de la politique italienne aidant, la raison d'État devint un objet de discussion « pour tout le monde ». Lorsque, en 1589, Giovanni Botero dédia son livre, le Della Ragion di Stato à l'archevêque prince de Salzbourg, il formulait, pour commencer, une observation digne "d'émerveillement», selon ses propres termes, rapportée de ses voyages auprès des cours des rois et des grands princes. « Tout le jour », affirmait-il, on parlait de la raison d'État citant soit Machiavel, soit Tacite: le premier parce qu'il offrait les préceptes du gouvernement et de la domination des peuples, le second car il exprimait, de manière vivante, les arts dont se servait Tibère pour maintenir son empire ${ }^{4}$. Cette observation s'intensifia jusqu'à provoquer l'indignation. Quand, en 1612, Traiano Boccalini publia la première centurie de ses Ragguagli di Parnasso, l'un était consacré à l'interprétation

1. BozzA, 1949. Dans ce recueil sont répertoriés les ouvrages consacrés à la réflexion sur l'État, sa constitution, l'action politique, son efficacité et ses difficiles rapports avec l'éthique, ainsi qu'à l'utopie. Les ouvrages moins politiques des mêmes auteurs, ceux notamment consacrés aux spéculations astrologiques, aux belles-lettres, etc., n'y figurent donc pas. Pour chaque référence, Bozza présente le titre de l'ouvrage, les éditions successives, éventuellement la rare présence dans les bibliothèques, le destinataire de la dédicace, la vie de l'auteur; il conclut avec une bibliographie. L'ensemble comprend 194 notices que l'on pourra compléter par le Dizionario biografico degli Italiani, 19692008 (désormais cité par l'abréviation $D B I$, suivie de l'indication du volume et des pages).

2. Guichardin, 1858, p. 211, «la ragione e uso degli Stati» (la raison et l'usage des État). Le traité a été rédigé autour des années 1521-1522. Voir Gino BenzonI, « Francesco Guicciardini », dans $D B I$, vol. LXI, p. 92; il ne semble pas avoir été publié à l'époque.

3. Dans son Orazione scritta a Carlo V Imperatore intorno alla restituzione della città di Piacenza, Della CASA, 1558, ici 1960, p. 476-480, oppose « la ragion civile » (la raison civile) à « la ragion di Stato » (la raison d'État), qu'il définit comme " falsa e dissoluta e disposta [...] a mal fare » (une raison fausse et dissolue, disposée... à mal faire), à laquelle a été assigné le gouvernement des empires. L'Orazione à Charles V fut rédigée à la fin de l'année 1548. Voir Claudio Mutins, « Giovanni Della Casa », dans DBI, vol. XXXVI, p. 711.

4. Botero, 1589 , ici 1997, p. 3 et 1559 , p. 1 vo, pour la traduction française. 
de Tacite par Juste Lipse: Tacite, seul auteur estimé digne des princes, passe aujourd'hui par les mains d'un chacun de telle sorte que même les petits marchands et les porteurs se montrent experts en raison d'État et tournent en dérision les grands hommes, tenus en la plus haute estime et jouissant d'une excellente réputation. Après quoi, Boccalini, renonçant à toute réserve, lançait la condamnation suivante : le monde entier est plein de «Politici Lerciamestieri ${ }^{5}$ ». Il récidiva encore quelque temps après, en 1616, dans une lettre adressée à un ami qui se trouvait dans l'entourage du nonce Bentivoglio à Paris ${ }^{6}$. Il y dénonçait fortement la corruption des sciences et des lettres en Italie.

Quant à la raison d'État, il insistait sur le fait que nombreux étaient ceux qui s'entretenaient de Tacite sans le comprendre ou parlaient de Machiavel sans l'avoir lu. Faisant référence aux vendeurs de poisson qui avaient attiré son attention, il concluait à propos de ces piètres politiques: «[...] leur nombre est quasi infini ${ }^{7}$. » La faute en était aux conseillers du prince.

Quelques années plus tard, en 1621, Lodovico Zuccolo réaffirmait le même point de vue: ceux qui n'ont jamais sillonné les mers ni composé d'opéra ne présument pas connaître l'art de la navigation ni la musique; mais certains, n'ayant jamais posé les pieds dans une cour de justice, ne connaissant pas les lois, n'ayant lu ni la politique ni l'histoire, prétendent, au même titre que les sénateurs et les princes, pourvoir aux affaires publiques. Par suite, il est arrivé que non seulement les conseillers dans les cours et les docteurs dans les écoles, mais aussi les barbiers et les gens de métier dans leurs boutiques et lieux de rendez-vous discutent de la raison d'État et se persuadent de savoir quelles choses se font par raison d'État et lesquelles ne se font pas ainsi ${ }^{8}$. Les auteurs qui, comme Zuccolo, s'efforçaient de définir et d'éclairer le plus finement qui soit la raison d'État, se sentaient molestés par des personnes auxquelles était déniée toute compétence en la matière. On se souvient pourtant du Don Quichotte et de son héros s'entretenant de la raison d'État avec un barbier notamment: Cervantès, marqué par ses expériences de soldat lors de la bataille de Lépante et d'esclave au bagne d'Alger, ne se priva pas, dans son chef-d'œuvre, d'une petite raillerie un peu amère sur la raison d'État ${ }^{9}$.

5. BocCaLInI, 1612-1613, I, 86, ici 1618, p. 282. Fougasses traduit l'expression par «politiques ignorans \& de nulle valeur » (BocCALINI, 1612-1613, ici 1615, p. 565).

6. BoccalinI, 1678, vol. III, p. 78-83 : Lettera IX. Al Signor Benedetto Cartani, Parigi. Rome, $13 / 11 / 1616$.

7. BocCaLINI, 1678, vol. III, p. 81.

8. ZuCCOLO, 1621, XI, p. 54.

9. Cervantès, 1605, ici 2001, p. 29: «Soy Sancho Panza, escude-,/del manchego don Quijo-;/ puse pies en polvoro-,/por vivir a lo discre-,/que el tácito Villadie-,/toda su razón de esta-/cifró en una retira-,/según siente Celesti-,/libro, en mi opinión, divi-,/si encubriera más lo huma-.» Le jeu de mot qui porte sur "razón de estado » semble intraduisible (les diverses traductions françaises consultées n'en rendent pas compte). Par le terme de «Villadiego », ici personnifié en homme discret (tacitiste?), Cervantès se réfère à une scène de La Célestine où un domestique conseille à un camarade de «tomar calzas de Villadiego ", expression familière signifiant fuir en toute hâte, sans mettre les chausses, en prenant la poudre d'escampette (voir Fernando de RoJas, La Célestine, acte XII). Dans Don Quichotte, le thème de la raison d'État apparaît explicitement dans un entretien entre le héros éponyme, le curé et un barbier. S'entretenant de la «razón de estado y modos de gobierno » (la raison d'État et des différents systèmes de gouvernement), chacun, tour à tour, corrigeait tel abus et condamnait tel autre, réformait telle coutume et bannissait telle autre: se comportant en législateur, chaque protagoniste se sentit finalement comme de nouveaux Lycurgue ou Solon. Mais qu'importait tout cela face à la menace turque, à ses 200000 soldats et à sa très grande flotte? Cervantès, en chantant les louanges des chevaliers errants, dépeint brièvement la raison d'État d'un trait satirique et aiguisé (voir CERvANTĖs, 1605, II, $1 ; 2001$, p. 625-639, pour le texte en espagnol; 1997, vol. II, p. 15-16, pour la traduction française). 
La voix de Cervantès n'exprimait évidemment pas l'attitude et l'opinion des auteurs ni de tous ceux qui s'intéressaient aux questions politiques. On ne connaît pas les catacombes de la littérature médiocre et oubliée dont parlait Meinecke ${ }^{10}$ et, moins encore, les discours des barbiers et des vendeurs de poisson. Le nombre d'auteurs relevé par Bozza apparaît déjà très considérable; les œuvres d'un bon nombre d'entre eux ont été analysées et sont bien connues. Quelques questions pourtant demeurent, même quant aux auteurs ayant remporté les plus grands succès, notamment face à leur mépris affiché envers les gens de simple condition. Quelles étaient leurs compétences et les motivations qui les décidèrent à prodiguer leurs vues sur le maniement de l'État, sa conservation, son éventuel agrandissement et donc sur la raison d'État? De quelle formation jouissaient-ils (traditionnelle et livresque ou pratique, par l'exercice d'un brin de pouvoir)? Suivaient-ils, ce faisant, une simple mode du jour? Quels ont été les effets produits par l'ensemble de ces traités? Est-ce que les hommes se sont laissé guider par ces ouvrages qu'on leur a souvent dédiés? Dans les pages qui suivent, nous essaierons d'apporter quelques éléments de réponse à ces interrogations, en scrutant l'arrière-fond de ces œuvres.

L'essor de cette littérature politique reposait sur différentes œuvres héritées d'époques antérieures. Les textes de Platon, d'Aristote et de Cicéron restaient toujours des objets de recherches; pour certains auteurs, toutefois, ils suscitaient plutôt des questions d'ordre philologique, tandis que les ouvrages proprement politiques se divisaient en deux courants : républicain et monarchique ou, plus précisément, princier. Francesco Patrizi vantait, dans deux ouvrages distincts, les avantages de la liberté républicaine, d'une part, puis ceux de la domination d'un seul, d'autre part ${ }^{11}$. L'apogée de cette littérature princière de la première moitié $\mathrm{du} \mathrm{XVI} \mathrm{X}^{\mathrm{e}}$ siècle est sans doute $\mathrm{Il}$ Principe de Nicolas Machiavel qui déclencha une controverse virulente. Nous abordons ici les auteurs qui prirent part aux débats politiques de l'époque, touchant la raison d'État, en fonction de leurs carrières, selon qu'ils furent ecclésiastiques, juristes, médecins, mathématiciens ou lettrés.

\section{LES AUTEURS ECCLÉSIASTIQUES}

L'un des principaux problèmes à affronter résidait dans la relation entre politique et éthique : l'Église devait donc, en premier lieu, y répondre - et ce, malgré sa propre politique qui ne tenait pas toujours compte des normes morales en vigueur. Tandis que Rome misait plutôt sur la répression en élaborant l'Index des livres prohibés, les intellectuels ecclésiastiques abordaient la question d'une manière plus argumentative. Parmi les cent trente-quatre auteurs italiens ${ }^{12}$ qui ont composé des écrits théoriques sur la politique, relevés par Bozza, pour la période allant de 1550 à 1650, pas moins de soixante-sept, c'est-à-dire 50\%, appartenaient à l'Église (qu'ils remplissaient de hautes fonctions, vivaient modestement en moines ou détenaient quelques bénéfices). Parmi eux, vingt-trois dépassaient par leur rang les autres auteurs. Ce groupe

10. MEINECKE, 1924, ici 1960, p. 78.

11. PATRIZI, 1518 et 1519.

12. Pour les biographies qui suivront, on se reportera aux notices de BozzA, 1949, et au DBI, 1960-2008. 
se composait de cinq archevêques dont deux cardinaux, huit évêques, trois abbés, un prieur, cinq protonotaires apostoliques tenant rang d'évêques ${ }^{13}$, et un magistrat de la rota mantouane. Leurs carrières furent très différentes, comme leurs écrits. Frédéric Borromée fut promu très tôt cardinal et il est difficile de ne pas penser à sa parenté avec saint Charles Borromée, ceci malgré ses propres mérites. Il reçut l'archevêché de Milan, comme Ascanio Piccolomini, qui était de la famille du pape Pie II, celui de Sienne. Robert Bellarmin ne pouvait pas compter sur de tel lien de parenté: le jésuite devait son ascension à l'enseignement et surtout à son rôle de censeur, ce qui lui valut le cardinalat et l'archevêché de Capri. Francesco Bonciani, au service notamment diplomatique du grand-duc de Toscane, reçut pour sa part l'archevêché de Pise. Le prédicateur et poète Marc'Antonio Querini détenait le titre d'archevêque de Naxos et de Paros.

Parmi les évêques, quatre s'étaient principalement consacrés à l'enseignement: Giovanni Antonio Viperani, Paolo Ciera, Celso Mancini et Raffaele Rastelli, lequel était également consulteur au Saint-Office. Un autre, Marco Girolamo Vida, était poète et fréquentait la cour de Léon X et Clément VII. Le diplomate Cesare Speciano fut d'abord au service de Charles Borromée: il lui conféra un canonicat à l'église métropolitaine de Milan, et l'envoya à Rome comme son agent. Référendaire à la segnatura apostolica et conseiller de la Congrégation des cardinaux, il fut assigné conseiller au nonce de Madrid, fait évêque, puis nonce auprès de Philippe II, légat à Prague auprès de l'empereur Rodolphe II ; il administra son dernier évêché. Giovanni Francesco Lottini, enfin, est une " figure typique d'aventurier ${ }^{14}$ ». Il fut, sa vie durant, en fuite. À l'âge de 17 ans, il commit son premier homicide; il connut, l'année suivante, son premier procès. À Rome, il prit les ordres mineurs et se fit ainsi ecclésiastique. Secrétaire particulier de Cosme ${ }^{\text {er }}$, grand-duc de Toscane, il fut l'instrument des intrigues et des délits de celui-ci. Renvoyé de Florence pour raison de sodomie, il se réfugia à Rome tout en restant au service de Cosme $\mathrm{I}^{\mathrm{er}}$. Nommé protonotaire apostolique et chanoine, il entra au service de divers cardinaux. Comme le souligne Bozza, « il fut toujours au milieu des intrigues et des assassinats ${ }^{15} »$. Accusé de rébellion et de crime de lèse-majesté, il fut torturé. Le nouveau pape le nomma évêque de Conversano, mais quatre mois après seulement il renonça à cet office.

Parmi le haut clergé régulier figure l'abbé de Guastalla, Bernardino Baldi: au service de saint Charles Borromée et du duc d'Urbino, notamment, il en devint le secrétaire. Il fut l'un des poètes didactiques les plus remarquables de la seconde moitié $\mathrm{du} X \mathrm{XI}^{\mathrm{e}}$ siècle. Le bénédictin Vincenzo Sgualdi fut professeur de philosophie à Milan et abbé de plusieurs monastères. Son admiration pour Venise lui valut de devenir citoyen et conseiller de cette République. Giacinto Gucci, abbé de Vallombrosa, enseigna comme orientaliste les langues à Florence et la théologie aux jeunes de sa propre

13. Les douze protonotaires apostoliques, officiers de la cour de Rome, avaient rang après les évêques et devant les abbés, se vêtaient des habits pontificaux et faisaient partie de la chapelle du pape. Leurs fonctions s'étendaient aux grands actes tels la prise de possession d'un nouveau pape, l'assistance à quelques consistoires et conciles, la canonisation de saints, la signature des bulles (voir Rigantius, 1751).

14. BozZa, 1949, ici 1980, p. 47.

15. BozZA, 1949, ici 1980, p. 47. 
congrégation. Malgré leurs rangs élevés, plusieurs tenaient à l'enseignement. Dans ce groupe restreint se trouvent des auteurs liés à Rome, Florence et Venise; en son sein, s'expriment aussi bien le catholicisme intransigeant d'un Bellarmin, la raison d'Église comme l'admiration républicaine, l'utopie d'un Sgualdi.

Parmi les deux tiers restants des auteurs ecclésiastiques, quatre dépassent par leur rang et leurs activités l'ensemble: Giovanni Botero, Antonio Possevino, Tommaso Bozio, Tommaso Campanella. Le premier, Giovanni Botero, était sans nul doute le plus proche des hommes du premier groupe. Entré jeune chez les jésuites, il enseigna à Billons en Auvergne, à Paris et à Milan, d'abord la rhétorique puis les Saintes Écritures. Après avoir appartenu pendant vingt ans à la Compagnie de Jésus, il en fut exclu sans avoir pu prononcer les vœux. L'archevêque de Milan, Charles Borromée, lui offrit la possibilité de collaborer à son œuvre de restauration catholique. En mission pour le duché de Savoie, il accompagna René de Lucinge en France. De retour à Milan, il se vit attribuer la charge de précepteur et conseiller du jeune Frédéric Borromée avec lequel il se rendit à Rome. De retour en Savoie, il fut le précepteur des enfants de Charles Emmanuel, qu'il accompagna en Espagne. Le duc lui assigna de 1604 à 1610 les revenus de l'abbaye de San Michele della Chiusa, alors détenue par un prince de la maison de Savoie. Il vivait à la cour de Turin comme secrétaire et conseiller. Milan, Rome et Turin furent donc les centres principaux de sa vie: malgré l'ambiance très catholique de ces cours, il trouva ses idéaux dans un " césaropapisme habsbourgeois », selon l'expression de Luigi Firpo ${ }^{16}$. Mais sa vision, très large, ne s'arrêtait pas à la Ragione di Stato ${ }^{17}$; ses observations et ses réflexions s'étendaient aux autres pays comme en témoignent les Relazioni universali ${ }^{18}$.

Un autre personnage de premier plan, Antonio Possevino, consacra ses efforts à la conversion des hérétiques. Après avoir été précepteur des enfants des Gonzague, il entra à la Compagnie de Jésus et partit en Piémont afin d'évangéliser les vaudois. Il passa dix ans en France où il déploya une grande activité contre les huguenots. De retour à Rome, il fut nommé secrétaire de l'ordre. Les grandes missions diplomatiques pour le Saint-Siège, en Suède, Russie, Pologne, Autriche et Transylvanie, se succédèrent. Pendant les dernières années de sa vie, il se retira à Padoue et se consacra à l'enseignement. Tommaso Bozio fut lui aussi un ardent propagateur de la ContreRéforme, un ennemi implacable de Machiavel et des protestants. Après avoir achevé des études de droit in utroque, c'est-à-dire en droit canon et en droit civil, il s'installa à Rome pour exercer la profession d'avocat. La rencontre avec Filippo Neri, fondateur de la congrégation de l'Oratoire, lui fit abandonner sa profession pour y entrer. Il coopéra, avec Cesare Baronio, aux Annales ecclesiasticae et publia un grand nombre de traités apologétiques et polémiques. Mieux connu, Tommaso Campanella a laissé parmi sa vaste production littéraire plusieurs écrits qui touchent à la question de la

16. Luigi FIRPO, « Giovanni Botero », dans DBI, vol. XIII, p. 360.

17. BOTERO, 1589.

18. BOtero, 1595. 
raison d'État, de la Monarchie d'Espagne ${ }^{19}$ aux écrits adressés aux princes d'Italie et à Louis XIII de France ${ }^{20}$.

Tous évidemment ont accompli des études de lettres et de théologie, quelques-uns de droit, parfois de médecine. Nombre d'entre eux se consacrèrent à l'enseignement (philosophie, morale, théologie), de manière ponctuelle ou leur vie durant, dans les écoles et les universités du Nord de l'Italie et de Rome, ou au sein de leurs ordres. On compte parmi eux dix-sept docteurs au moins. Il s'agissait le plus souvent de doctorats en philosophie et en théologie; sept ont obtenu un doctorat en droit, in utroque, et un en médecine. Pietro Andrea Canonieri cumulait les doctorats en philosophie, médecine et théologie; Paganino Gaudenzi en théologie, philosophie et droit. Deux doctorats furent conférés à Gentile Bongiovanni, qui fut reçu docteur en philosophie et en théologie à Graz en Autriche, et à Lelio Zecchi, en théologie et en droit à Paris. Après leurs études, bon nombre d'ecclésiastiques se mettaient au service comme secrétaire notamment chez les cardinaux, ce qui pouvait les conduire à des ambassades. Certains, qui appartenaient au clergé régulier, faisaient carrière dans les ordres ou les congrégations, et un bon nombre recevait de la part de leurs patrons de riches canonicats; d'autres, encore, se consacraient à la prédication et acquéraient ainsi une grande réputation. Canonieri, pour sa part, avait plus ou moins perdu ses liens avec la théologie et exerçait la profession de médecin. Scipione Chiaramonti, mathématicien et philosophe, connu pour son opposition aux grands scientifiques de l'époque, de Kepler à Galilée, n'embrassa l'état ecclésiastique que dans la vieillesse. Contrairement à ce que l'on pouvait attendre, le nombre des jésuites était très réduit. Sept seulement appartenaient à la Compagnie de Jésus: Robert Bellarmin, Giovanni Botero, Anton Giulio Brignole Sale, Antonio Ciccarelli, Giovanni Stefano Menochio, Antonio Possevino et Giovanni Antonio Viperani - deux, Botero et Viperani, quittèrent même l'institution.

Leur petit nombre ne correspondait évidemment pas à leur influence réelle et au véritable pouvoir qu'ils exerçaient: ce pouvoir était largement représenté par la figure du grand censeur que fut Bellarmin; et, Ciccarelli, par exemple, appartenait à ceux qui avaient pour fonction de « corriger » les livres que l'Inquisition se chargeait d'expurger pour les rendre acceptables. Les jésuites Bellarmin, Botero et Possevino, de même que l'oratorien Bozio agissaient parfaitement dans le sens de la Contre-Réforme, mais Rome ne formait qu'un centre intellectuel parmi d'autres. Les études, le service chez les grands, l'enseignement universitaire, l'appartenance à un ordre religieux avaient obligé ces auteurs à une très grande mobilité ${ }^{21}$. Il est donc malaisé de vouloir les rattacher à un ou deux centres intellectuels : ces derniers étaient nombreux ; certains étaient

19. Campanella, 1620. L'ouvrage écrit en italien fut imprimé du vivant de l'auteur en allemand. On se référait alors à l'édition allemande réalisée par Christoph Besold, qui est la première édition de la Monarchie d'Espagne. C'est à partir de celle-ci qu'a été établie l'édition latine du texte parue vingt ans plus tard. Pour plus de détail, voir l'introduction de Germana ERnst à CAMPANELla, 1620, ici 1997, p. VII-XLVIII.

20. Luigi FIRPO, « Tommaso Campanella », dans DBI, vol. XVII, p. 372-401. Voir les notices de BozZA, 1949, ici 1980, p. 133-136, 141-143, 171-172, 202-203, et tout récemment DelumeAu, 2008, p. 419-474.

21. Ce ne fut pas, toutefois, le cas de Campanella qui connut un sort terrible et passa près de trentecinq ans en prison. 
particulièrement attrayants, comme les cours romaines du pape et des cardinaux, le Milan des Borromée, la Florence des Médicis, les cours d'Urbino et de Ferrare, des Este et des Della Rovere, et bien sûr Venise. Cette République représentait un idéal opposé à celui de Rome, celui de l'aristocratie et de la liberté22.

\section{LES JURISTES}

À côté de l'Église qui, provoquée par Machiavel, se devait de réagir promptement, on trouve les juristes: la tâche de répondre aux exigences politiques de l'époque leur incombait également. En effet, depuis le XIII ${ }^{\mathrm{e}}$ siècle, les juristes s'étaient érigés en de véritables gestionnaires de l'État administratif naissant ${ }^{23}$. On pouvait donc attendre de leur part des réflexions poussées sur les entités étatiques qu'ils pouvaient observer. Le résultat de l'enquête ne confirme guère cette hypothèse. Seulement trente-trois auteurs ont eu une formation juridique ${ }^{24}$. Treize appartenaient à l'état ecclésiastique, vingt furent donc des laïques. Parmi les cinq protonotaires apostoliques (six avec Lottini), quatre pouvaient se prévaloir du titre de docteur, tandis que dix laïques avaient mené leurs études jusqu'au doctorat (un autre était devenu docteur en théologie). Le profil des carrières des laïques se présentait d'une manière différente que celui des carrières des ecclésiastiques. Seulement quatre ont pris goût à l'enseignement; quatre autres avaient une activité d'avocat, au moins temporairement. La judicature et l'administration, exercées soit dans les villes où ils résidaient soit en tant que gouverneur, les attiraient beaucoup plus. Sept avaient opté pour cette voie. Le savant vénitien Sebastiano Erizzo, numismate, fut sénateur, membre du Conseil des Dix, Savio di Terraferma ${ }^{25}$. Girolamo Manfredi assuma la charge de gouverneur de Ravenne, de Cesena et de Faenza. Le plus célèbre de ce groupe, Boccalini, exerça les charges de gouverneur de Benevento, maire de Trevi, juge au tribunal du gouverneur au Campidoglio, puis reçut le gouvernement de quelques villes dans l'État pontifical. Fulvio Paccini, après avoir été en charge d'un petit gouvernement, obtint la fonction de capitano di giustizia à Sienne. Raffaele Della Torre fut quatre fois sénateur à Gênes.

Un cas particulier mérite d'être mentionné. Massenzio Carbonari, après son doctorat de droit, s'était enrôlé dans la milice pontificale où il resta pendant 25 ans : il fut promu gouverneur de Città di Castello et de Fabriano, puis protonotaire apostolique ${ }^{26}$. Pour faciliter leur ascension sociale, plusieurs ont cherché à obtenir des charges chez les grands : chez les cardinaux, les Médicis, le souverain pontife, voire même à la cour du roi d'Espagne. Ainsi le docteur Annibale Scotti, d'abord au service des Farnèse, devint

22. L'abbé Sgualdi la dépeignit sous le nom de république de Lesbos, voir SGUALdi, 1640.

23. CREMER, 1999a.

24. On ne compte pas ici le cas de Lottini: bien qu'il porta, un certain temps, les habits liturgiques de protonotaire apostolique, il ne reçut pas véritablement de formation juridique; il fut, bien plus, l'homme des basses œuvres du grand-duc de Toscane et du pape.

25. Les « Sages de terre-ferme » appartenaient au Collegio dei Savi, organe de la république de Venise.

26. Bien qu'il n'ait vraisemblablement pas fait des études de théologie, Carbonari a été compté ici parmi les ecclésiastiques en raison de la position de protonotaire apostolique (celle quasiment d'un évêque) qu'il occupait. 
cameriere segreto (camérier secret) de Sixte Quint. Francesco Sansovino ne répondait pas à cette règle générale: il préféra la vie de polygraphe docte et d'éditeur à Venise. Virgilio Malvezzi, homme politique et écrivain fécond, mérite une mention particulière ${ }^{27}$. Jeune docteur in utroque jure, il entra au service militaire espagnol au duché de Milan, devint sénateur de Bologne et s'embarqua en 1636 pour l'Espagne où il fut nommé historiographe officiel; il entra au Conseil de guerre de Philippe IV, puis au Conseil collatéral de Naples, enfin au Conseil d'État de Milan. Après une ambassade extraordinaire en Angleterre, il fut attaché au cardinal infant gouverneur des Pays-Bas espagnols avec la tâche de rassembler les opposants contre Richelieu. Après la disgrâce de son grand mécène à Madrid, le comte et duc d'Olivares, Gaspar de Guzmán, il retourna à Bologne, où il reprit les fonctions de sénateur auxquelles il ajouta encore celles de gonfaloniere di giustizia. Pendant toute cette vie très agitée, il n'avait jamais interrompu sa production politico-littéraire, restant en étroite liaison avec les intellectuels qui prenaient une part active dans les débats sur la question littéraire. La carrière du Piémontais Charles Paschal est également digne d'intérêt: après des études de jurisprudence, il s'attacha aux grands personnages parisiens, notamment à Guy du Faur de Pibrac, avocat général au parlement de Paris puis président à mortier. Henri III et Henri IV le chargèrent de plusieurs missions et négociations. Il fut reçu avocat général au parlement de Rouen, pour se voir enfin confier l'ambassade des Grisons pendant dix ans ${ }^{28}$.

Une distinction notable réside entre les carrières des laïques et des ecclésiastiques : ces derniers trouvèrent plus régulièrement des emplois chez des patrons, notamment auprès des cardinaux qu'ils accompagnaient dans leurs voyages et missions diplomatiques avant de se voir confier de telles charges. En outre, par leur formation en droit civil et canon, les juristes pouvaient se prévaloir d'une plus grande expérience dans le maniement des affaires publiques; en revanche, peu s'enthousiasmaient pour des formes de gouvernement républicain comme Venise. Plusieurs, cependant, offrent des contre-exemples: Giuseppe Bonfadio, attaché à l'enseignement vénitien; l'érudit Erizzo, administrativement haut placé au sein de la République; l'éditeur Sansovino; Boccalini qui, après avoir passé toute sa vie à Rome, se réfugia à Venise. Dans ses Ragguagli di Parnasso, parus à Venise, Boccalini laissa libre cours à sa puissance imaginative de juriste en faisant d'Apollon le juge de tous les écrivains, parmi lesquels les auteurs politiques appelés à comparaître au tribunal du mont Parnasse.

\section{LES MÉDECINS ET LES MATHÉMATICIENS}

Venant d'un tout autre horizon, quelques médecins et mathématiciens avaient également abordé le problème de la raison d'État. Parmi les auteurs italiens considérés, on compte six médecins - quelques-uns jouissant, à leur époque, d'une grande réputation. Canonieri, précédemment mentionné, pratiqua la médecine pendant de longues années à Anvers; deux autres ont exercé à Venise. Certains commencèrent par l'enseignement de la philosophie ou de la logique. Le docteur Filippo Cavriani suiva Louis de Gonzague,

27. Voir Clizia CarminatI, « Virgilio Malvezzi», dans DBI, vol. LXVIII, p. 336-342.

28. BozZa, 1949, ici 1980, p. 56-57; voir également Fumaroli, 1994. 
duc de Nevers, en France où il s'éleva à l'office d'archiatre (médecin en chef) de la cour de France ${ }^{29}$. Ses activités en faveur du grand-duc de Toscane, peu appréciées par Henri III, l'obligèrent à retourner en Italie où il obtint la chaire de médecine théorique à Pise. Le plus éminent des médecins fut sans aucun doute Lodovico Settala. Dès 1575, il occupait la chaire de médecine à Milan. Outre son activité d'enseignement universitaire et la rédaction d'un bon nombre d'ouvrages, il se distingua par son assistance aux pestiférés en 1576 et fut nommé protofisico (premier médecin) de l'État de Milan. En 1630, il fut lui-même atteint par la peste. Son ouvrage sur la Ragion di Stato parut en 1627 ; il était alors âgé de 73 ans. Pour sa part, Federico Bonaventura, bien qu'ayant publié plusieurs ouvrages sur la médecine, ne peut être raisonnablement compté parmi les médecins: toutes ses publications concernant la médecine sont des travaux de pure philologie, des recueils de citations tirées notamment d'Aristote et de Théophraste, sans le moindre lien avec la pratique de cet art. Campanella, en revanche, avait suivi des cours de médecine à Padoue et publié des ouvrages en la matière.

Quant aux mathématiciens, trois figures s'imposent. Francesco Patrizi, auteur de la Nouvelle Géométrie, appliqua la méthode géométrique à des objets non mathématiques $^{30}$. Bernardino Baldi, poète didactique de très grande renommée, fut également auteur d'œuvres d'histoire et de mathématiques ${ }^{31}$. Enfin, le plus fameux, Scipione Chiaramonti, est connu pour sa farouche opposition à l'astronomie moderne, à Tycho Brahé, Kepler et Galilée notamment. Il publia son traité sur la Ragion di Stato en 1635, alors qu'il était âgé de $70 \mathrm{ans}^{32}$.

\section{LES LETTRÉS}

Trente-sept auteurs n'entrent pas dans les catégories mentionnées ci-dessus. En majorité, ces auteurs ont mené des études de lettres et de philosophie qui formaient alors la base de toute éducation; certains ont poursuivi dans cette voie et enseignaient eux-mêmes. L'enseignement ne se réduisait pas alors seulement à une question d'érudition: il impliquait celle du mécénat de l'autorité politique, le service de cour étant compatible avec l'enseignement. Parmi ce groupe, dix-sept auteurs étaient attachés d'une manière ou d'une autre à une cour, en tant que secrétaire ou conseiller d'État, membre du Sénat ou chargé d'ambassades. Parmi ces cours, on relève celles de Ferrare, Urbino, Florence, Naples et Turin, ainsi que la cour d'Espagne; la cour pontificale, en revanche, se trouvait pratiquement hors du jeu.

Les carrières politiques pouvaient prendre des tournures fort différentes. Francesco Lanario, par exemple, débuta une carrière militaire. Après avoir achevé ses études à Naples, il s'enrôla comme capitaine de cavalerie dans l'armée espagnole aux Pays-Bas où il resta pendant sept années. La cour de Madrid où il séjourna à plusieurs reprises, lui octroya honneurs et charges. Ainsi fut-il nommé membre du Conseil de guerre des

29. Gino BenzonI, « Filippo Cavriani », dans $D B I$, vol. XXIII, p. 151-157.

30. Sur la géométrie de Patrizi, voir GerL, 1982.

31. Raffaele Amaturo, « Bernardino Baldi », dans $D B I$, vol. V, p. 461-464.

32. Gino BenzonI, « Scipione Chiaramonti », dans DBI, vol. XXIV, p. 541-549. 
Flandres, gouverneur de la province de Lecce, vicaire de Catania, gouverneur civil de la Basilicata, duc de Carpiñano et chevalier de Calatrava ${ }^{33}$. Paolo Paruta, éminent représentant de la république de Venise, une fois ses études de philosophie et d'éloquence achevées, fonda une académie privée des sciences politiques et morales. Il fut ensuite chargé de l'administration de la camera degli imprestiti (chambre des prêts), nommé gouverneur de Brescia, puis ambassadeur à Rome, où il officia en faveur de la reconnaissance d'Henri IV par le pape. Il fut enfin nommé procuratore de Saint-Marc et devenait ainsi l'un des principaux magistrats de la République vénitienne.

Alde Manuce (le Jeune), fils de Paolo, imprimeur et érudit, enseigna dans le monde des lettres. Son activité de type éditoriale le plongea au cœur de ce monde duquel certains auteurs semblaient rester plus éloignés: l'administrateur des grains et des huiles à Naples, Giulio Cesare Capaccio, par exemple, ou encore, le maître des courriers de sa Majesté Très-Chrétienne, le roi de France, à Venise, Alessandro Vidali. Pour sa part, Ottavio Sammarco, baron de la Rocca et de Camino, vivait, étudiait et écrivait sur ses terres.

La poésie, enfin, constituait une activité répandue parmi l'ensemble des groupes mentionnés. À première vue difficilement conciliable avec la matière des traités de raison d'État, bon nombre de ces auteurs avait en fait publié des rimes, des comédies, des tragédies, des poèmes héroïques, des favole boschereccie (fables pastorales). Bien que la plupart de ces œuvres ne soient généralement plus connues - comme celle de Gabriele Zinano, émule de Torquato Tasso, qui estimait surpasser son maître -, d'autres jouissent toujours d'un grand renom: c'est le cas notamment des œuvres de Sperone Speroni, de Bernardino Baldi et surtout de Battista Guarini, connu pour son Pastor fido. Le cavaliere Guarini fut, en outre, un homme très avisé en matières d'État et un courtisan recherché ${ }^{34}$.

\section{LES MOTIVATIONS}

Le vaste panorama, brièvement décrit ci-dessus, permet de constater que, toutes catégories réunies, le niveau intellectuel des écrivains politiques de l'époque était en général très élevé. En outre, plusieurs appartenaient à des académies qui florissaient alors en Italie ou en avaient même fondé, tel Paolo Paruta. Les cours princières stimulaient également l'échange et la discussion. L'appartenance à une université ne convenait pas à tout le monde. On y faisait ses études, mais certains refusaient de passer le doctorat, comme Paruta et Guarini - ce dernier trouvant déshonorant d'accepter une nomination de professeur, bien qu'il eût dans sa jeunesse enseigné. L'université pourtant pouvait mener plus loin: « [...] l'enseignant y est en effet un aspirant courtisan ${ }^{35}$. » Le but suprême de toute carrière était l'appartenance à une cour princière, ecclésiastique ou laïque, comme secrétaire ou conseiller ${ }^{36}$.

33. Outre Lanario, d'autres auteurs ont assumé des fonctions militaires, au moins temporaires : Pier Maria Contarini, par exemple, prit part à la guerre de Chypre.

34. Elisabetta SELmI, « Battista Guarini », dans DBI, vol. LX, p. 345-352.

35. BENZONI, 1998, p. 137.

36. Brizzi, 1998; Benzoni, 1998; Ago, 1990; Calcaterra, 2004. 
Compte tenu de ces éléments, et des carrières parfois très brillantes de ces auteurs, une question demeure: quels étaient les motifs qui les poussaient à publier une telle quantité d'ouvrages sur la politique? La rédaction de ces réflexions, de ces recueils de maximes et concetti, fondés sur l'interprétation des auteurs de l'Antiquité, est souvent décrite par leurs auteurs comme une fatica (fatigue): l'expression revient si souvent dans les dédicaces qu'elle désigne, en certains cas, l'œuvre elle-même; elle en devient synonyme. Pour quelles raisons ces auteurs ont-ils accepté d'endurer pareille peine? Des éléments de réponse se trouvent dans les épîtres dédicatoires, les avertissements aux lecteurs, les préfaces. Les ouvrages publiés du vivant des auteurs sont, en général, précédés d'une dédicace qui pouvait remplir plusieurs fonctions. Traduisant tantôt la soumission à l'autorité du dédicataire, tantôt l'expression de remerciements pour de bonnes grâces reçues, elle exprimait en premier lieu la recherche de la protection d'un puissant seigneur contre d'éventuels adversaires - c'est-à-dire, en somme, surtout contre l'Inquisition. Sansovino offre un exemple en la matière qui s'approche fort d'un hommage féodal. Dédiant son Governo et amministratione au duc Orsini di Bracciano, il l'assurait de le reconnaître comme son suprême seigneur, de le révérer et honorer toujours, avec tout son cœur et toutes ses forces ${ }^{37}$. Dans son Davide proseguitato, Malvezzi assurait Philippe IV de sa dévotion ${ }^{38}$. Dans une lettre adressée à Giovanni Battista Marini, Boccalini s'exprimait clairement sur cette recherche de protection ${ }^{39}$. Dans sa dédicace au cardinal Caetano, il déclarait se sentir, par cette protection, à l'abri d'homme téméraire qui oserait censurer ses peines ${ }^{40}$. Palazzo, pour sa part, voyait dans ce procédé une manière de combiner habilement publicité et protection ${ }^{41}$. Toutefois, ce procédé s'imposait aux auteurs lorsque les ouvrages composés étaient le fruit d'une commande, comme ce fut le cas du Prencipe de Frachetta ${ }^{42}$. La pratique qui consistait à dédicacer les ouvrages comportait un risque pour l'auteur puisque le prince, certes honoré, était alors invité à s'informer des moyens d'une politique efficace: ce geste pouvait être interprété comme une mise en doute de ses capacités. Frachetta et Palazzo, comme beaucoup d'autres, soulignèrent expressément les grandes connaissances, le discernement, la prudence, l'habileté, etc., de leurs dédicataires en la matière ${ }^{43}$. Nombre d'ouvrages étaient explicitement destinés aux conseillers, aux secrétaires et à ceux qui entouraient les princes.

Certains auteurs ressentaient le devoir de justifier leurs compétences. Malvezzi, né en 1595, publia ses Discorsi sopra Cornelio Tacito en $1622^{44}$. Un aussi jeune homme pouvait-il être un bon écrivain politique? Répondant par l'affirmative, Malvezzi affirmait qu'un vieillard de 100 ans connaissait ce qu'il avait vu et écouté pendant sa vie, alors que celui qui avait lu et étudié les histoires avait accès aux choses principales

37. SANSOVIno, 1578b. Les textes préliminaires ne comportent généralement pas de pagination.

38. MALVEZZI, 1634.

39. BoCCALINI, 1678, vol. III, p. 66.

40. BocCalini, 1612-1613, II. Boccalini faisait ici référence à la fatica mentionnée ci-dessus. Voir, de même, Chiaramonti, 1635.

41. Palazzo, 1604 (voir sa dédicace à Fabrizio di Sangro, duc de Vietro).

42. FrachetTA, 1597. L'ouvrage lui fut commandé par le duc de Sessa, alors ambassadeur auprès du Saint-Siège.

43. Voir Frachetta, 1597; Palazzo, 1604.

44. MALVEZZI, 1622. 
advenues jusqu'à son époque. À l'inverse de Malvezzi, Settala chercha à expliquer les raisons qui le décidèrent à publier un traité de raison d'État à un âge avancé ${ }^{45}$. Ayant observé avec soin les faits et les actions des princes comme des républiques, ayant lu les historiens et les écrivains politiques de diverses nations et de langues différentes, Settala estimait avoir rassemblé un savoir digne d'être transmis. Il avait par ailleurs exposé, depuis une vingtaine d'années déjà, son interprétation de l'Éthique à Nicomaque et de la Politique d'Aristote devant ses auditeurs des scuole canobiane, ces écoles publiques de rhétorique, logique, philosophie et morale, cédées en 1624 aux jésuites.

Si l'on prête attention aux buts avoués des traités, leurs auteurs semblent avoir une haute opinion de leur tâche. Scipione Ammirato, par exemple, concevait sa faculté de mettre par écrit ses réflexions sur la félicité des peuples comme un don de Dieu, qui lui aurait été concédé pour le profit d'autrui ${ }^{46}$. Frédéric Borromée se sentait obligé par son état, les années, la charge et les offices qu'il remplit, non par l'espoir d'une grâce ou d'une bienveillance qu'un homme de pouvoir aurait pu lui concéder ${ }^{47}$. D'autres, en revanche, rédigeaient leurs traits pour favoriser leur carrière. Ainsi, le jeune Malvezzi n'hésitait pas à concéder qu'il n'avait rédigé ses Discorsi que pour se faire connaître du grand-duc de Toscane ${ }^{48}$. Sansovino, pour sa part, se présentait comme un curieux observateur des grands hommes ${ }^{49}$ : un motif que Gabriel Naudé reprendra quelques décennies plus tard dans ses Considérations politiques sur les coups d'État citant des vers du Trinummus de Plaute sur le plaisir d'observer les dieux et d'écouter leurs bavardages ${ }^{50}$.

Cet aspect de la question revêtait une grande importance, la plupart des auteurs l'abordaient avec discernement. On peut distinguer plusieurs types d'argumentations. La plus répandue était celle qui prodiguait des conseils afin que les ministres accomplissent leurs tâches de manière efficace, à la fois pour eux-mêmes et pour la félicité de leurs peuples. La «regia sapientia» de Botero appelait à la bonté du prince chrétien, catholique $^{51}$; le prince était parfois représenté tel un Salomon régnant ${ }^{52}$. Après la publication de Tacite par Juste Lipse en 1574 et son commentaire paru quelques années plus $\operatorname{tard}^{53}$, le courant tacitiste prit son essor. L'éditeur se vantait lui-même d'avoir fait d'une philologie une philosophie ${ }^{54}$. Commentant l'histoire de Tibère dans les premiers livres des Annales, cette philosophie mettait au centre de sa réflexion l'efficacité, l'utilité, la prudence, la simulation, la dissimulation, la conservation et l'accroissement de l'État. Ce courant comptait, parmi les auteurs les mieux connus et plus analysés, Paschal,

45. Settala, 1627. Comme il le soulignait lui-même, Settala était alors âgé de 73 ans (voir supra, p. 435).

46. Ammirato, 1594.

47. Borromée, 1632.

48. MalvezZI, 1622.

49. SANSOVINO, $1578 \mathrm{~b}$.

50. NAUDÉ, 1639 , ici 1988, p. 83.

51. BOTERO, 1583.

52. MaLipiero, 1639.

53. LIPSE, éd., 1574 et 1581.

54. « Ego è Philologiâ Philosophiam feci », cité dans Cremer, 1999b, p. 547. 
Ammirato, Canonieri, Boccalini ${ }^{55}$. Un petit groupe vantait, au contraire, les avantages de la liberté: Uberto Foglietta, Ansaldo Cebà, Alde Manuce, Paolo Paruta, Vincenzo Sgualdi, Lodovico Zuccolo. Sgualdi composa un véritable panégyrique sur Venise ${ }^{56}$. Zuccolo, lui aussi admirateur de la Sérénissime, récusa le fondement des autres formes de gouvernement: selon cet auteur, les lois romaines, transmises et utilisées par des hommes sans lettres et faibles d'esprit, étaient issues de la corruption des mœurs du peuple et de décrets promulgués par de cruels tyrans ${ }^{57}$.

Giuseppe Bonfadio désignait les adversaires de l'aristocratie: Bodin, Barclay, Lipse $^{58}$. Chez les hauts représentants de l'Église et quelques autres auteurs, un amalgame mêlant différents ennemis de l'orthodoxie se forma: les hérétiques luthériens pour Bellarmin ${ }^{59}$, Machiavel pour Botero ${ }^{60}$, Bozio $^{61}$ et Albergati qui ne le nommait même pas et le désignait seulement comme le secrétaire florentin ${ }^{62}$; Bodin pour Boccalini ${ }^{63}$; Machiavel et Bodin pour Possevino ${ }^{64}$ et Castiglione ${ }^{65}$; Machiavel, Bodin, La Noue, Tacite pour Vanozzi ${ }^{66}$, etc. Les auteurs ici incriminés, en particulier Machiavel et Tacite, représentaient les ennemis par excellence qu'il convenait de combattre ouvertement. Dans ce combat, certains ne se fiaient pas aux doctrines nouvelles et s'en remettaient aux Saintes Écritures ${ }^{67}$; les ecclésiastiques tournaient leurs efforts vers un renforcement de la puissance du souverain pontife ${ }^{68}$.

Enfin, l'éducation constituait une préoccupation partagée par l'ensemble de ces auteurs politiques. On la trouvait, d'une manière générale, chez les auteurs comme Sansovino, par exemple, convaincus que les actions des hommes de tous les temps ont toujours été les mêmes et que l'on pouvait, par conséquent, tirer des leçons de l'histoire ${ }^{69}$. D'une manière plus précise, Ansaldo Cebà consacra son Cittadino di Republica à la jeunesse de Gênes ${ }^{70}$. D'autres saisirent l'occasion pour prodiguer leurs conseils aux enfants princiers. Ainsi, Lucio Paolo Roselli, juriste, poète et orateur, dédia son petit traité Il Ritratto del vero governo del Prencipe dal l'essempio vivo del gran Cosimo de'Medici à François de Médicis, fils aîné de Cosme IIr. L'opuscule vantait l'exemple et les vertus du père, notamment sa prudence, tout en soulignant que la plus grande félicité des hommes était d'avoir des princes bons et prudents ${ }^{71}$. Giovanni Battista Pigna

55. Voir Momigliano, 1955 ; Meinecke, 1924; Schellhase, 1976; Catteeuw, 2007.

56. SGUALDI, 1640 .

57. ZuCCOLO, 1623, p. 253.

58. BONFADIO, 1611.

59. Bellarmin, 1619.

60. Botero, 1589. Pour cet auteur, à Machiavel se joignait Tacite.

61. BozIO, 1593 et 1595 .

62. Albergati, 1627.

63. BoCCALINI, 1612-1613, ici 1618, notamment I, 64, p. 196-203. Voir également CremER, $1976 \mathrm{~b}$.

64. Possevino, 1592

65. Castiglione, 1628.

66. VANNOZZI, 1609-1613.

67. Meroni, 1615 et 1637; Menochio, 1625.

68. CARIERI, 1599; Ciera, 1607.

69. Voir SANSOVInO, 1578a.

70. CEBÀ, 1617.

71. Roselli, 1552. Roselli entretenait une relation épistolaire avec Melanchthon (voir BozzA, 1949, ici 1980, p. 33). 
fut un familier du prince héritier de Ferrare pour lequel il avait rédigé un Principe qu'il publia en 1561 et dédia au jeune duc de Savoie. Il s'était donné pour but de former un prince dont la réputation ne se fonderait pas sur la force et l'étendue de son empire, mais sur la vertu, la légitimité et un gouvernement prudent ${ }^{72}$. Le comte Paolo Brusantini rédigea ses Dialoghi de'Governi pour son fils : il y expliquait les positions du « principalissimo Ministro » et des quatre premiers « cavalieri » de cour ${ }^{73}$. Le cardinal Bellarmin adressa son De officio principis christiani à Ladislas Sigismond III, fils du roi de Pologne ${ }^{74}$. L'abbé Raimondo Silvestri fit de même avec les princes de Parme $^{75}$; l'augustinien Adeodato Solera, avec le prince héritier, son familier et courtisan ordinaire ${ }^{76}$. Le Principe bambino du bénédictin Valeriano Castiglione ${ }^{77}$ et le Principe studioso de Tommaso Tomasi, professeur de logique à la Sapienza, s'inscrivent dans la même démarche ${ }^{78}$. Nonobstant le scepticisme d'un Zuccolo, par exemple, sur la valeur des études académiques ${ }^{79}$, l'ensemble des traités touchant la question de la raison d'État présente un fort élément pédagogique.

L'Italie du $\mathrm{XVI}^{\mathrm{e}}$ siècle était morcelée en une multitude d'entités étatiques, dominées par des princes auxquels la légitimité manquait souvent. La réponse à cette situation a été cherchée dans deux courants de la pensée politique à première vue opposés : l'idée - remontant à Pétrarque - d'un État unifié et fort ou, au contraire, se soumettant à la réalité telle qu'elle existait. En ce dernier cas, il s'agissait avant tout de définir les moyens par lesquels ces petits États et leurs princes pouvaient survivre. L'œuvre de Machiavel déclencha un débat concernant l'efficacité de l'action politique qui se traduisit par le développement d'une vaste littérature. D'un côté, la défense des valeurs morales contre Machiavel prévalait; d'un autre côté, la tentative de rationaliser l'État s'imposait. Par-delà leur opposition, certains auteurs ont tenté de combiner ces deux démarches; quelques-uns créèrent des utopies. Les écrivains politiques poursuivaient des intérêts divers. L'Église et les cours princières détenaient les clés de l'ascension sociale en distribuant d'innombrables postes de secrétaire, conseiller, professeur, ambassadeur, etc. Il fallait se faire connaître, soit en soutenant la Contre-Réforme, si l'on visait une carrière ecclésiastique, soit en proposant des modes d'action efficaces pour entrer au service d'un prince. Bon nombre d'auteurs, parmi les ecclésiastiques, soutenaient une raison d'État chrétienne par conviction contre l'immoralité supposée de Machiavel et la liberté de conscience requise par Bodin. Les multiples traités de pédagogie politique, précédemment évoqués, corroborent cet aspect.

Il semble difficile d'apprécier l'influence des traités de raison d'État sur la politique et, de manière plus générale, sur la rationalisation de l'État. Elle paraît, toutefois, plutôt

72. PIGNA, 1561.

73. BRUSANTINI, 1611.

74. Bellarmin, 1619.

75. Silvestri, 1619.

76. SOLERA, 1628.

77. Castiglione, 1634.

78. Tomasi, 1643. Ce traité fut rédigé pour Cosme de Médicis, grand-duc de Toscane.

79. Zuccolo déclarait avoir «plus lu qu'étudié » et préférer la fréquentation des sénateurs et cavalieri à celle des docteurs (VOIR ZuCCOLO, 1621, ici 1623, «L'auttore à chi legge », non paginé). 
limitée; ceci, pour plusieurs raisons. Bien que quelques auteurs ont réellement exercé des fonctions administratives, la très grande majorité prodiguait un savoir livresque. Girolamo Frachetta, par exemple, dans son Seminario de' Governi, se vantait d'avoir mis à la disposition des princes quelques 8000 maximes politiques tirés des auteurs classiques afin qu'ils soient toujours en mesure de trouver la solution adéquate à une situation donnée ${ }^{80}$. Certes, son opuscule, Il Prencipe, était plus facile à manier ${ }^{81}$. Toutefois, les destinataires de ces traités, le duc de Ferrare ou le grand-duc de Toscane, par exemple, fouillaient-ils vraiment ces grands recueils de concetti, d'avvertimenti dont se délectait Sansovino ${ }^{82}$ ? L'effort pédagogique de quelques auteurs ne semble guère avoir réussi à distraire les jeunes princes de la vie et des conversations de cours. Malgré de notables différences de points de vue, d'idées et de conceptions entre ces divers traités, une certaine conformité de pensée, reposant sur un fonds classique et chrétien, se dégage de cet ensemble. Même si chez certains auteurs, tels Botero et Sansovino, émergeait un intérêt comparatif et statistique pour les divers États ${ }^{83}$, l'écrasante majorité des traités et des maximes d'État ne s'éloignait guère des chemins mille fois battus. Ainsi de graves problèmes restaient sans solution: celui notamment de la mise à mort, pour raison d'État, des milliers de prisonniers de guerre - telle que perpétrée après la bataille d'Azincourt (1415), telle que recommandée avec insistance par Guichardin à l'encontre de $\mathrm{Pise}^{84}$, telle que divulguée à un large publique par Shakespeare dans son Henry $V$. Face au problème moral posé par la raison d'État, tous ces auteurs, y compris les juristes, se résignaient encore pour longtemps.

Les choses ont-elles changées en Italie suite à cette avalanche de traités ? On n'oserait guère le confirmer. La rationalisation de l'État a puisé à d'autres sources. D'abord, on observe que les grands États, mis à part l'Empire ottoman - l'Angleterre, la France, l'Espagne et les principaux membres du Saint Empire romain germanique - n'ont connu une telle littérature qu'à une échelle réduite. La France, le véritable modèle de l'État «moderne », tout en subissant l'influence italienne, avait plutôt suivi les analyses formulées de Jean Bodin à Cardin Le Bret. Si l'on prête attention aux bibliothèques des magistrats du Parlement de Paris, à ce groupe qui poussait le plus l'État vers sa rationalisation, on constate que la littérature sur la raison d'État n'y était que faiblement représentée. Plus que la simple volonté du prince, ce sont les structures administratives, dont les officiers se trouvaient investis par l'inamovibilité et la vénalité des charges, qui ont constitué les bases élémentaires de l'État moderne. Il reste, pourtant, que les traités italiens de la raison d'État, même s'ils étaient rédigés par des ecclésiastiques, ont assumé « cette nécessaire instruction de mal en politique ${ }^{85}$ ». Ce faisant, ils ont largement contribué au «déniaisement» de la politique et donc à la laïcisation de l'État.

\footnotetext{
80. FrachetTA, 1613.

81. FrachetTA, 1597.

82. SANSOVINO, 1583.

83. Senellart, 1995, p. 55-59; Descendre, 2009.

84. Guichardin, 1858, p. 211.

85. Catteeuw, 2007, p. 384 sqq.
} 


\section{LISTE DES RÉFÉRENCES}

\section{I- Sources}

Albergati (Fabio), 1627, La Republica regia, Bologne, Benacci.

Ammirato (Scipione), 1594, Discorsi sopra Cornelio Tacito, Florence, Giunti, rééd. Venise, Valentino, 1607.

Bellarmin (Robert), 1619, De officio principis christiani, libri tres, Rome, Ex typographia Bartholomaei.

Boccalini (Traiano), 1612-1613, Ragguagli di Parnaso, Venise, rééd. Venise, Guerigli, 1618; Les Cent Premières Nouvelles et advis de Parnasse, trad. franç. Th. De Fougasses, Paris, Adrien Perire, 1615.

Boccalini (T.), 1678, La Bilancia politica di tutte le opere, Castellana, Widerhold, 3 vol.

Bonfadio (Giuseppe), 1611, De civilis administrationis optima forma, Patavii, Laurentium Pasquatum.

Borromée (Frédéric), 1632, Il Libro intitolato la Gratia de’ Principi, Milan.

Botero (Giovanni), 1583, De Regia sapientia libri tres, quibus ratio Reipub. bene faeliciterque administrandae continetur, Milan, Pontius.

Botero (G.), 1589, Della Ragion di Stato, Venise, Gioliti, éd. Chiara Continisio, Rome, Donzelli, 1997; Raison ou gouvernement d'Estat en dix livres, trad. franç. de Gabriel Chappuys, Paris, Guillaume Chaudière, 1599.

Botero (G.), 1595, Delle Relationi universali, Rome, Ferrari, rééd. Venise, Polo, 1597-1598.

Bozıo (Tommaso), 1593, De Imperio virtutis sive imperia pendere a veris virtutibus, non simulatis, libri duo adversus Macchiavellum, Rome, Bonfadini, rééd. Cologne, Gymnich, 1601.

Bozıo (T.), 1595, De Italiae statu antiquo et novo libri quatuor adversus Macchiavellum, Rome, Bonfadini, rééd. Cologne, Gymnich, 1598.

Brusantini (Paolo), 1611, Dialoghi de' Governi, Modène, Giulian Cassiani.

Campanella (Tommaso), 1620, Von der Spanischen Monarchy Oder Aussführliches Bedencken welcher massen von dem König in Hispanien zu nunmehr lang gesuchter Weltbeherrschung sowol insgemein als auff iedes Königreich und Land besonders allerhand Anstalt zumachen sein mochte..., s.1.; De Monarchia Hispanica Discursus, Amsterdam, 1640; Monarchie d'Espagne, Monarchie de France, trad. Serge Waldbaum, Nathalie Fabry, éd. Germana ERnst, Paris, Presses universitaires de France, 1997.

CARIERI (Alessandro), 1599, De potestate Romani Pontificis adversus impios politicos, libri duo, Patauij, Franc. Bolzetam.

Castiglione (Valeriano), 1628, Statista regnante, Lyon.

Castiglione (V.), 1634, Il Principe bambino, Turin, Tarino.

CевÀ (Ansaldo), 1617, Il Cittadino di Republica, Gênes, Pavoni, rééd. Venise, Combi, 1620.

Cervantès (Miguel de Cervantes Saavedra), 1605, Don Quijote de la Mancha, éd. Francisco Rico, Barcelone, Crítica, 2001; L’Ingénieux Hidalgo Don Quichotte de la Manche, trad. Aline Schuman, Paris, Le Seuil, 1997, 2 vol.

Chiaramonti (Scipione), 1635, Della Ragione di Stato. Nel qual trattato da' primi principij dedotto si scuoprono appieno la natura, le massime, e le specie de' Governi buoni, e de' attivi, e mascherati, Florence, Nesti.

Ciera (Paolo), 1607, Tractatus de jure Principum, Bononiae, Ioannis, Rossij.

Della Casa (Giovanni), 1558, Orazione scritta a Carlo V Imperatore intorno alla restituzione della città di Piacenza, Venise, rééd. dans Castiglione (Baldassare), Della Casa (Giovanni) et Cellini (Benvenuto), Opere, éd. Carlo Cordié, Milan/Naples, Ricciardi, 1960, p. 474-491. 
FrachetTa (Girolamo), 1592, L'Idea del libro de' governi di Stato e di guerra ... con due discorsi, l'uno intorno la ragione di Stato, l'altro intorno la ragion di guerra, Venise, Denaro.

FrachetTa (G.), 1597, Il Prencipe, nel quale si considera il Prencipe, \& quanto al governo dello Stato, \& quanto al maneggio della guerra, Rome, Mutij, rééd. Venise, Ciotti, 1599.

FrachetTA (G.), 1613, Il Seminario de' Governi di Stato, \& di guerra, nel quale sotto cento dieci capi si comprendono intorno a otto mila massime, ò proposizioni universali, \& regole, ò insegnamenti di Stato, \& di guerra, Venise, Deuchino, rééd. Paris, 1648.

Guichardin (François), 1858, Opere inedite, vol. II: Del Reggimento di Firenze, Florence, Barbèra.

Lipse (Juste), éd., 1574, C. Cornelii Taciti Historiarum et Annalium libri quae exstant, Justi Lipsii emendati..., Anvers, Plantin.

Lipse (J.), 1581, Ad Annales Corn. Taciti liber commentarius, sive notae, Anvers, Plantin.

Malipiero (Federico), 1639, Il Salomone regnante, Venise, Gasparo Corrodici.

Malvezzi (Virgilio), 1622, Discorsi sopra Cornelio Tacito, Venise, rééd. Venise, Ginami 1635.

Malvezzi (V.), 1634, Davide proseguitato, Bologne, Monti, rééd. Bologne, 1636.

Menochio (Giovanni Stefano), 1625, Hieropoliticon sive institutionis politicae e Sacris Scripturis depromptae libri tres, Lugduni, Ludovici Prost.

Meroni (Paolo Giuseppe), 1615, Pauli Iosephi Meroni presbyteri mediolanensis ad aulicos et principes commentarii in psalmum, Lugduni, Ex typographia Iacobi du Creux.

Meroni (P. G.), 1637, Pauli Iosephi Meroni ad aulam davidicam in psalmo centesimo descriptam exercitationes sive de optimo principe, liber unus, Rome.

NAUdÉ (Gabriel), 1639, Considérations politiques sur les coups d'États, rééd. Louis Marin, Paris, Les Éditions de Paris, 1988.

Palazzo (Giovanni Antonio), 1604, Discorso del governo e della ragion vera di Stato, Naples, Sottile, rééd. Venise, De'Franceschi, 1606; Discours du gouvernement et de la raison vraye d'Estat, trad. franç. Adrien de VAlLières, Douay, Baltazar Bellere, 1611.

PARUTA (Paolo), 1600, Discorsi politici. Ne i quali si considerano diversi fatti illustri, e memorabili di Principi, e di Republiche Antiche, e Moderne, Gênes, Pavoni.

Patrizi (Francesco), 1518, De Institutione reipublicae libri novem hystoriarum sententiarumque varietate refertissimi, Paris, Galliot Du Pré, rééd. Strasbourg, Zetzner, 1594.

Patrizi (F.), 1519, De Regno et regis institutione, opus profecto et historiarum varietate et sententiarum gravitate commendandum, Paris, Galliot Du Pré, rééd. Strasbourg, Zetzner, 1594.

PIgNa (Giovanni Battista), 1561, Il Principe, nel quale si discrive come debba essere il Principe Heroico, sotto il cui governo un felice popolo possa tranquilla \& beatemente vivere, Venise.

Possevino (Antonio), 1592, Iudicium de nuae militis Galli scriptis, quae ille discursus politicos, \& militares inscripsit. De Ioannis Bodini Methodo historiae: Libris de Repub. \& Daemonomania. De Philippi Mornei libro de Perfectione Christiana. De Nicolao Machiavello, Rome, Typographia Vaticana.

Rigantius (Joseph), 1751, De protonotariis apostolicis tam de numero partecipantium quam supranumerum necnon titularibus seu non partecipantibus dissertationes postuma, Rome, Palearini.

Roselli (Lucio Paolo), 1552, Il Ritratto del vero governo del Prencipe dal l'Essempio vivo del gran Cosimo de' Medici, con due orationi d'Isocrate conformi all'istessa materia, tradotte dal medesimo di Greco in volgare Italiano, Venise, Bonelli.

SAnsovino (Francesco), 1578a, Concetti politici. Raccolti da gli scritti di diversi autori greci, latini, \& volgari, à beneficio \& commodo di coloro che attendono à governi delle Republiche, $\&$ de Principati, in ogni occasione cosi di guerra, come di pace, Venise, Bertano. 
Sansovino (F.), 1578b, Del Governo et amministratione di diversi regni et republiche, cosi antiche come moderne, libri XXI. Ne'quali si contengono diversi ordini, magistrati, leggi, costumi, historie, \& altre cose notabili, che sono utili \& necessarie ad ogno huomo civile \& di Stato. Con nuova aggiunta di piu republiche \& regni in diverse parti del mondo, Venise, Bertano.

SAnsovino (F.), 1583, Propositioni, overo considerationi in materia di cose di Stato, sotto titolo di Avvertimenti civili, \& concetti politici di M. Francesco Guicciardini. M. Gio. Francesco Lottini. M. Francesco Sansovini. Di nuovo posti insieme, ampliati, \& corretti, à commodo \& benefitio degli Studiosi. Nelle quali si contengono, leggi, regole, precetti, \& sentenze molto utili à coloro che maneggiano, cosi i Principati \& le Republiche, come ogni altra sorte di governo, Venise, Salicato.

Settala (Lodovico), 1627, Della Ragion di Stato libri sette, Milan; De Ratione Status libri septem, Hambourg, Pfeiffer, 1659.

Sgualdi (Vincenzo), 1640, Republica di Lesbo. Overo della ragione di Stato in un Dominio aristocratico libri dieci, Bologne, Tebaldini, rééd. Bologne, Benacci, 1646.

Silvestri (Raimondo), 1619, Il Principe infante overo dell'educazione del Principe, Francfort, Matthias Perlin.

Solera (Adeodato), 1628, I Memoriali di Stato, Naples, Lazaro Scoriggio.

Tomasi (Tommaso), 1643, Il Principe studioso, Venise, Gio. Battista Suria.

Vannozzi (Bonifacio), 1609-1613, Della Suppellettile degli avvertimenti politici, morali et christiani, Bologne, Heredi Rossi.

Zuccolo (Lodovico), 1621, Considerationi politiche, e morali sopra cento oracoli d'Illustri personaggi antichi. Nelle quali, con insegnamenti di Aristotile, con autorità di Cornelio Tacito, e d'altri scrittori politici si discorre di varie materie pertinenti al governo de gli Stati, alla introdottione de' buoni costumi, \& alla cognitione dell'Historie, Venise, Capponi, rééd. Venise, Marco Ginami, 1623.

Zuccolo (L.), 1623, Discorsi dell'honore, della riputatione, della gloria, del buon concetto, Venise, Ginami.

II - Études

Ago (Renata), 1990, Carriere e clientele nella Roma barocca, Rome/Bari, Laterza.

BEnzoni (Gino), 1998, «À la recherche de l'identité: entre université et académie », dans Fumaroli, dir., 1998, p. 125-141.

Bock (Gisela), 1974, Thomas Campanella. Politisches Interesse und philosophische Spekulation, Tübingen, Niemeyer.

Bozza (Tommaso), 1949, Scrittori politici italiani dal 1550 al 1650. Saggio di bibliografia, rééd. Rome, Edizioni di Storia e Letteratura, 1980.

Brizzi (Gian Paolo), 1998, « Collèges, académies, écoles privées. Expériences d'enseignement extra-universitaire en Italie (1450-1550) », dans Fumaroli, dir., 1998, p. 109-122.

Calcaterra (Francesco), 2004, La Spina nel guanto. Corti e cortigiani nella Roma barocca, Rome, Gangemi.

CAtteeuw (Laurie), 2007, «La modernité de la raison d'État et le masque du temps », Revue de synthèse, $\mathrm{n}^{\circ} 3-4$, p. 369-394.

CREMER (Albert), 1976a, «Les théoriciens italiens de la raison d'État juges de Jean Bodin », Revue d'histoire diplomatique, $\mathrm{n}^{\circ}$ 89, p. 249-261.

Cremer (A.), 1976b, « Traiano Boccalini als Kritiker Bodins », Quellen und Forschungen aus italienischen Archiven und Bibliotheken, vol. 55-56, p. 229-250. 
CREMER (A.), 1999a, « La genèse de la notion de noblesse de robe », Revue d'histoire moderne et contemporaine, $\mathrm{n}^{\circ} 46$, p. 22-38.

Cremer (A.), 1999b, «Tra'1 Moral Seneca \& il Politico Tacito. Die Krise des Christentums in Frankreich 1580-1630 », dans LeHMANN (Hartmut) et TREPP (Anne-Charlott), dir., Im Zeichen der Krise. Religiosität im Europa des 17. Jahrhunderts, Göttingen, Vandenhoeck und Ruprecht, p. 543-557.

DesCENDRE (Romain), 2009, L'État du monde. Giovanni Botero entre raison d'État et géopolitique, Genève, Droz.

Delumeau (Jean), 2008, Le Mystère Campanella, Paris, Fayard.

Dizionario biografico degli Italiani, 1969-2008, Rome, Istituto della Enciclopedia Italiana, 70 vol.

Fumaroli (Marc), 1994, « La prose de l'État: Charles Paschal, théoricien du style royal. Rhétorique et politique à la cour de France sous Henri III et Henri IV », dans ID., La Diplomatie de l'esprit. De Montaigne à La Fontaine, Paris, Hermann, p. 59-124.

Fumaroli (M.), dir., 1998, Les Origines du Collège de France (1500-1650). Actes du colloque international (Paris, décembre 1995), Paris, Collège de France/Klincksieck.

GerL (Hanna-Barbara), 1982, « Humanistische und geometrische Sprachphilosophie. Ein Paradigmenwechsel von Leonardo Bruni zu Francesco Patrizi », Zeitschrift für Philosophische Forschung, vol. XXXVI, n ${ }^{\circ}$, p. 189-207.

MeINECKE (Friedrich), 1924, Die Idee der Staatsräson in der neueren Geschichte, rééd. Walther HoFer, Munich, Oldenbourg, 1960; L'Idée de la raison d'État dans l'histoire des Temps modernes, trad. Maurice CHEvalliER, Genève, Droz, 1973.

Momigliano (Arnaldo), 1955, «The First Political Commentary on Tacitus », dans ID., Contributo alla storia degli studi classici, Rome, Edizioni di Storia e Letteratura, vol. I, p. 37-59.

Schellhase (Kenneth C.), 1976, Tacitus in Renaissance Political Thought, Chicago/Londres, The University of Chicago Press.

Senellart (Michel), 1992, «La raison d'État antimachiavélienne. Essai de problématisation », dans LAZZERI (Christian) et ReYNiÉ (Dominique), dir., La Raison d'État : politique et rationalité, Paris, Presses universitaires de France, p.15-42.

Senellart (M.), 1995, Les Arts de gouverner. Du regimen médiéval au concept de gouvernement, Paris, Le Seuil. 